\title{
Nova forma de dominação ou cena potente? Uma análise das relações entre Juventude e Ação Cultural na Periferia Urbana Brasileira
}

\author{
Nueva forma de dominación o de una escena de gran alcance? \\ Un análisis de la relación entre la Juventud y Acción Cultural \\ en la periferia urbana brasileña
}

\section{New form of domination or powerful scene? An analysis of the relationship between Youth and Cultural Action in the Brazilian Urban Periphery}

\author{
Vinicius Carvalho Lima1
}

Palavras chave:

Periferia

Juventude

Ação Cultural
Resumo:

O objetivo deste artigo é investigar, a crise da dicotomia centro-periferia associada a emergência de iniciativas culturais na periferia urbana brasileira, estimuladas por políticas do Ministério da Cultura (MinC). A dicotomia centro-periferia desenvolvida na América Latina como uma tentativa de explicar o crescimento acelerado/desorganizado e o lugar das classes populares afastadas da possibilidade de moradia perto do núcleo da metrópole, sofreu diversas mudanças ao longo dos últimos 50 anos. A investigação dessas mudanças e a consideração renovada dos atores sociais, nos leva a notar a emergência de uma produção cultural juvenil periférica e a consequente descompressão do imaginário legado a essas regiões, ligados exclusivamente ao precário em suas variadas dimensões. O que modifica, inclusive, a cena política, com questões e demandas diferentes das tradicionais. Pretende-se aqui analisar a efetividade dessas políticas na reprodução social da "juventude periférica" brasileira, tomando como caso específico a análise sociológica realizada através do contato com jovens de Nova Iguaçu/RJ. O foco central é a produção de análises que avancem no entendimento do que se modifica e/ou permanece com relação à periferia urbana/juventude nos níveis conceitual e contextual, em sua face progressista e perversa, dado a multiplicação de diferentes expressões urbanísticas e socioculturais nestes espaços das metrópoles. 


\section{Resumen:}

El objetivo de este trabajo es investigar la crisis de la dicotomía centroperiferia asociado con la aparición de iniciativas culturales de la periferia urbana brasileña, alentados por las políticas del Ministerio de Cultura (MinC). La dicotomía centro-periferia desarrollado en América Latina como un intento de explicar el crecimiento acelerado / desorganizado y el lugar de las clases trabajadoras fuera de la posibilidad de una vivienda cerca del centro de la metrópoli, ha sufrido varios cambios en los últimos 50 años. La investigación de estos cambios y una nueva consideración de los actores sociales, nos lleva a observar la aparición de una producción cultural juvenil y descompresión consecuente legado imaginario periférico en dichas regiones, ligadas exclusivamente a los pobres en sus diversas dimensiones. Lo que cambia, incluyendo la escena política, con preguntas y demandas diferentes de los tradicionales. La intención aquí es analizar la eficacia de estas políticas en la reproducción social de la "juventud periférico" brasileño, tomando como caso concreto el análisis sociológico realizado a través del contacto con los jóvenes de Nova Iguaçu / RJ. El foco central es la producción de análisis que el avance del entendimiento de lo que cambia y / o permanece en relación con los urbanos periféricos / juventud niveles conceptuales y contextuales, en la cara progresista y perversa, dada la proliferación de diferentes expresiones en estos urbano y sociocultural espacios de la metrópoli.
Palabras clave:

Periferia

Juventud

Acción Cutural

\section{Keywords:}

\section{Periphery}

Youth

Cultural Action

\section{Abstract:}

The objective of this article is to investigate the crisis of center-periphery dichotomy associated with the emergence of cultural initiatives in the Brazilian urban periphery. The center-periphery dichotomy that has been developed in Latin America as an attempt to explain the accelerated growth / disorganized and the place of the working classes away from the possibility of housing near the core of the metropolis, has undergone several changes over the past 50 years. The investigation of these changes and the renewed consideration of the social actors, leads us to notice the emergence of a youth cultural production and consequent decompression of peripheral imagery legacy to those regions, linked exclusively to the poor in its various dimensions. What changes, also the political scene, with questions and demands different from the traditional. The intention here is to analyze the effectiveness of these policies in the social reproduction of youth peripheral Brazil, taking case specific sociological analysis conducted through contact with young people from Nova Iguaçu / RJ. The central focus is the production of analyzes that advance the understanding of what changes and / or remains in relation to the urban periphery / youth in the conceptual and contextual levels, in your face progressive and perverse, given the multiplication of different expressions in these urban and sociocultural spaces of the metropolis. 


\section{Nova forma de dominação ou cena potente? Uma análise das relações entre Juventude e Ação Cultural na Periferia Urbana Brasileira}

\section{Introdução}

Este artigo parte de investigação realizada para dissertação de mestrado defendida no Instituto de Pesquisa e Planejamento Urbano e Regional (IPPUR/ UFRJ), com apoio decisivo do Laboratório da Conjuntura Social: tecnologia e território (LASTRO-IPPUR/UFRJ)2. Seu objetivo é analisar a crise da dicotomia centro-periferia associada a emergência de iniciativas culturais que tem como foco a juventude na periferia urbana brasileira.

A investigação dessas mudanças e a consideração renovada dos atores sociais, nos leva a notar a emergência de uma produção cultural juvenil periférica e a consequente descompressão do imaginário legado a essas regiões, ligados exclusivamente ao precário em suas variadas dimensões. O que modifica inclusive a cena política, com questões e demandas diferentes tradicionais.

Pretendemos analisar a efetividade dessas políticas na reprodução social da juventude periférica brasileira, tomando como caso específico a análise realizada através do contato com jovens de Nova Iguaçu/RJ. Trata-se da tentativa de produzir análises que avancem no entendimento do que se modifica e/ou permanece com relação à periferia urbana/juventude nos níveis conceitual e contextual, em sua face progressista e perversa, dado a multiplicação de diferentes expressões urbanísticas e socioculturais nestes espaços das metrópoles.

Nesse sentido, dividimos o artigo em três partes. A primeira dedicada à reflexão sobre a Periferia Urbana e suas diferentes interpretações; uma segunda parte dedicada à análise das políticas culturais nos anos Luís Inácio Lula da Silva e sua chegada à cidade de Nova Iguaçu e por fim analisaremos o impacto dessas políticas na produção de subjetividades dos jovens periféricos em suas potencialidades e limites.

\section{Centro-periferia: uma dicotomia em crise}

Nesta primeira parte, como assinalado anteriormente, procuraremos refletir sobre a crise da dicotomia centro-periferia tal como formulada pelas escolas clássicas do pensamento urbano. $O$ modelo dicotômico centro-periferia foi pensado inicialmente para clarificar o processo de dominação dos países periféricos pelos países centrais. No inicio da década de 1970 , com o surgimento de estudos inovadores ${ }^{3}$ que relacionaram o crescimento econômico à organização da estrutura urbana, a noção de periferia passou a ser trabalhada em diferentes escalas. Consolidava-se nesta época um processo de urbanização acelerado e concentrado, promovida por um tipo de industrialização que conjugava a modernização dos parques industriais (com maior produtividade) e formas precárias de trabalho, o que levou a uma intensa concentração urbana em toda a América Latina.

Deste modo, a segregação espacial, promovida pelo crescimento das metrópoles, revelou a sua face social, através da definição da função da periferia: o espaço que abriga aqueles que ocupam posição de baixa remuneração e qualificação e que não podem pagar pela habitação dos espaços centrais, apesar de neles trabalharem. A periferia urbana partindo dessa matriz analítica foi caracterizada, pela literatura acadêmica, como um espaço socialmente homogêneo, habitado por uma população de baixa escolaridade, que autoconstruiria 
suas casas em lotes comprados ás custas de endividamentos de longo prazo.

Obra que apresenta os fundamentos da dicotomia centro-periferia clássica no campo da análise marxista ${ }^{4}$, "A questão urbana", de Manuel Castells ([1972], 1983), revela que a organização espacial da cidade está conectada a práticas sociais resultantes de conflitos entre as classes sociais urbanas. Assim, a disputa pelo poder (político, social e econômico) aparece na disputa pelo controle, uso e ocupação do espaço. Cada fração do espaço abrigaria, portanto, representações sociais específicas, estabelecidas através da relação capital-trabalho.

A sociedade dividida em classes através e sob o modo capitalista de produção teria sua materialização clara com a localização dos indivíduos através de seu status social, profissional, renda e instrução. A segregação urbana se expressa espacialmente, portanto, através de regiões homogêneas e fortes internamente, porém díspares socialmente. $O$ conceito de segregação urbana torna-se então central na compreensão da produção e apropriação do espaço da cidade. O espaço urbano nessa perspectiva é entendido como uma parte de um sistema de maiores proporções que compreende a formação social do capitalismo (GOTTDIENER, 1997).

O ponto divergente dessa síntese analítica oriunda de Castells ([1972], 1983) - para a reflexão proposta - é a compreensão da reprodução das relações sociais. Não há uma distinção clara entre a produção da cidade no modo de produção capitalista - que gera sem dúvida uma periferia carente - e as relações sociais tecidas nesses espaços. É como se a carência na periferia urbana estivesse naturalmente "acoplada" aos indivíduos.

Não se trata de negar a dialética centro-periferia reconhecida pelo pensa- mento marxista dedicado ao fenômeno urbano; mas, sim de reconhecer os seus usos instrumentais e a sua absorção pelo senso comum. Usos instrumentais de leituras presas à materialidade permitiram o desconhecimento da complexidade e colaboraram na despolitização da questão urbana, mesmo que a situação periférica seja denunciada. Estabelece-se uma recusa da complexidade e, assim, uma tendência a simplificar a realidade social a partir de uma interpretação, também simplista, do espaço. Trata-se de uma aceitação sem criticas do denominado espacialismo, com forte rebatimento na construção das identidades sociais e culturais.

Nesse sentido, cabe destacar a contribuição de Henri Lefebvre ([1973], 1983), este autor procura afastar a noção de segregação das noções de diferença e separação. Para ele, a diferença corresponde a relações percebidas ou concebidas, enquanto a separação e a segregação estão ligadas a uma ideia de rompimento da relação. O arcabouço conceitual de Lefebvre foi construído através do conceito de reprodução das relações sociais, ou seja, a reprodução ampliada do capital é também a reprodução ampliada das contradições sociais.

O essencial, portanto, não é a descrição de processos parciais (como o processo da produção material e a avaliação quantitativa do consumo), mas, a análise das relações sociais e da sua reprodução. As relações sociais, portanto, exercem papéis mais relevantes do que a organização espacial das cidades está destinada, o que exige o estudo do tecido social das áreas segregadas.

Deste modo, os modelos explicativos que relegam a periferia e seus moradores à margem e como frutos do crescimento urbano desordenado tornam-se simplistas e pouco explicativas já que a periferia carente - considerando as rela- 
ções sociais na perspectiva lefebvriana - pode tanto conformar as classes populares, a medida que os bairros se reproduzem com os mesmos valores em uma sucessão de gerações; como pode ser um elemento revolucionário na medida em que a percepção da exclusão desvelada pelo cotidiano se traduza de alguma maneira em luta por direitos ${ }^{5}$.

Por esses caminhos analíticos as periferias - consideradas no plural porque se tratam de muitas e distintas - emergem como espaços transformadores, diferentemente do que faz crer o diagnóstico de seus problemas. A possibilidade de mobilização política de seus moradores e, como pretendemos, de mobilização cultural, é um trunfo na tentativa de promover coesão e integração social através de iniciativas distantes das soluções padrão aplicáveis a temática da segregação urbana.

\section{Emergência da produção cultural periférica}

Embora historicamente a heterogeneidade de situações periféricas seja imensa, a desvalorização simbólica (BOURDIEU, 1999) da periferia permitiu/ permite a consolidação de mecanismos de discriminação e de preconceitos, com apoio de imagens homogêneas e negativas. Evidências aparecem por toda parte de que a representação corrente da periferia como lugar de subserviência está ultrapassada.

Nessa direção, cabe dizer que, enquanto as análises sociológicas, geográficas e urbanísticas tomavam como ponto de partida mecanismos estruturais ou de natureza econômica, a antropologia ${ }^{6}$ se debruçava sobre o espaço periférico para investigar atores, modos de vida, cotidiano, formas de lazer, identidades culturais, mobilizações coletivas e processos de subjetivação (NASCIMENTO, 2010). Na perspectiva de Magnani (2006), estudos antropológicos buscaram ver a cidade "de perto e de dentro", valorizando o ator social, em contraste com as análises orientadas pelas outras disciplinas sociais.

Com o surgimento desses novos conteúdos na análise da periferia, cria-se um campo temático que dá destaque à produção cultural periférica como um fenômeno contemporâneo relevante, ressaltando especialmente os mercados paralelos que proliferaram à margem da indústria cultural hegemônica (VIANNA, 1997).

Atores vêm conquistando presença na cena política, apresentando novas questões e demandas diferentes das tradicionais (por infraestrutura e serviços), reivindicando políticas culturais específicas e estabelecendo conexões tanto entre sujeitos periféricos como, também, entre estes e representantes dos centros geográfico, político e cultural.

Esse momento, se não totalmente possibilitado, teve grande influência do incremento das políticas culturais brasileiras, a partir da gestão Gilberto Gil/ Juca Ferreira no Ministério da Cultura (MinC). Estas políticas, nos últimos dez anos têm sido marcadas pela tentativa de resgaste do Estado enquanto formulador e implementador.

Nos anos 2000, modificam-se as palavras de ordem do setor. A diversidade cultural e seus desdobramentos (multiculturalismo, política descentralizada e participação popular, por exemplo) emergem como conceitos e diretrizes, que, de alguma forma soam como imediatamente justos, democráticos e progressistas ${ }^{7}$.

Nessa conjuntura, a gestão Gil primou pela busca de superação das falhas na formulação das políticas culturais no Brasil. De inicio, nota-se a mudança de paradigmas em relação ao entendimen- 
to da cultura. O MinC teria, como uma de suas missões, o trabalho com um conceito ampliado de cultura ${ }^{8}$.

Nesse sentido, o Estado toma a frente da definição de estratégias para a área da cultura e o planejamento estratégico de médio e longo prazos. Assume-se, portanto, a relevância que a cultura enquanto política pública passaria a ter na agenda do governo. Havia necessidade de rearrumar as relações entre as diferentes esferas de governo para a gestão da cultura, já que o MinC, por isso só, preso em sua estrutura precária, não alcançaria, em sua atuação, a abrangência necessária. O ministério ${ }^{9}$ então descentraliza as ações, à medida que assume a coordenação e a formulação das diretrizes para a área cultural, posicionado como mediador das demandas sociais.

No entanto, neste processo, apesar dos avanços, percebemos alguns problemas. O primeiro foi a inabilidade/impossibilidade do governo em transformar suas políticas em políticas de Estado, o que garantiria sustentação e continuidade do trabalho com a cultura. Outro ponto é a discussão das políticas culturais orientada pelo modelo UNESCO - é sintomático que muitos países e seus secretários, profissionais e artistas da cultura tenham aderido tão rapidamente aos chamados para as convenções promovidas por esta instituição - está posta a necessidade de dar vazão as manifestações culturais e a criação de alternativas para exclusão de suas respectivas sociedades.

No entanto, está clara também a busca pela construção de uma alternativa de mercado. Em outras palavras, critica-se o modelo neoliberal de acesso desigual à cultura mediado pelo mercado e adota-se a produção cultural como forma de desenvolvimento e competição no mesmo mercado. Ao mesmo tempo em que se valoriza a diversidade e todo de- bate por detrás dela, o que parece é que se busca a conformação de nichos para que indivíduos e sua produção cultural possam ser encaixados.

Propomos, portanto, pensar o quanto esses projetos das grandes organizações mundiais estão demarcados por ideologias de mercado que nada tem a ver com política cultural e proteção das manifestações culturais e artísticas. No Brasil, atenuam-se essas contradições ideológicas pelos anos que a política cultural ficou somente presa as leis de incentivo. Contribuíram a oportunidade de participar das discussões esperada por muito tempo e a escolha de Gilberto Gil para o ministério nome consensual.

O objetivo não é criticar a retomada do Estado frente as políticas culturais brasileiras, até porque, no caso das políticas culturais, este vem trabaIhando na direção contrária durante há quase um século. No entanto, é preciso enxergar as discussões e possibilidades que existem por detrás do campo das ações/políticas culturais mesmo que nos mostremos satisfeitos com as (pequenas) mudanças realizadas. Ainda se faz necessária uma política cultural real e amplamente pensada pelo Estado em diálogo com a sociedade civil, sem a imediata delegação de seu trabalho à outras organizações e sem que um dos eixos principais seja a economia da cultura/criativa - ou seja relacionar à cultura, incluindo sua criação e seu fazer, como algo que tenha que ter, necessariamente, algum impacto econômico.

\section{O caso de Nova Iguaçu}

De forma imediata, nota-se que a eleição de Lindberg Farias e seus dois mandatos (2004-2010) pelo Partido dos Trabalhadores (PT) foram fundamentais para busca e implementação das políticas 
e iniciativas culturais na cidade de Nova Iguaçu, a partir da tentativa de alinhar sua gestão a linha política estratégica de seu partido, que naquele momento iniciava sua primeira administração no país. Nova Iguaçu ganha, assim, novo posicionamento no jogo político da Região Metropolitana do Rio de Janeiro (RMRJ).

A eleição de Lindberg reacendeu e fomentou o debate político no âmbito do município, em um processo eleitoral que ultrapassou suas barreiras e teve amplo destaque nos meios de comunicação, movendo lideranças nacionais de partidos de oposição e situação, que foram ao município sempre que se percebeu a necessidade de apoio aos candidatos de suas respectivas coligações (BARRETO, 2006 e SIMÕES, 2007).

Durante a sua gestão, ficou clara a tentativa de Lindberg de alinhar suas políticas ao que estava sendo feito pelo governo no âmbito federal. As secretarias municipais passaram a ter perfis diferentes, já que foram empossados em sua maioria secretários/pessoal com históricos próximos das áreas temáticas das respectivas secretarias ${ }^{10}$. A busca de verbas em diversas instâncias torna-se um objetivo; seja em órgãos e agências transnacionais ${ }^{11}$, seja dos ministérios em Brasília, para onde muitos de seus assessores e funcionários foram para se qualificar e buscar recursos nos diversos programas do governo federal.

A Secretaria de Cultura e Turismo (SEMCTUR), talvez, foi a que obteve maiores ganhos nesta conjuntura. De esquecida nos governos anteriores, relegada a programação/divulgação de eventos, passou a lugar em que foram criados projetos com articulações próprias. A SEMCTUR adquire importância na conjuntura do município, principalmente, a partir da prioridade dada ao Bairro-Escola e também pela aproximação das políticas do Ministério da Cultura, como o Programa Cultura Viva.

As políticas do MinC foram o modelo do processo de institucionalização da SEMCTUR. Foi criada uma política espeIhada com editais para pontinhos de cultura. Essas políticas foram pensadas para os espaços periféricos da própria da cidade. Os editais que foram confeccionados determinavam que os projetos devessem ser divididos igualmente entre as diferentes URGs da cidade.

Essas políticas, apesar de não terem esse corte definido, foram abraçadas pela juventude da cidade. Seja pela participação e ganho dos recursos dos editais por iniciativas que já existiam no município e que trabalhavam com jovens como o Movimento Enraizados ${ }^{12}$, seja pelos novos pontos e pontinhos que estimularam a participação da juventude. Dentro deste contexto foram criadas duas iniciativas da SEMCTUR que me propus analisar detidamente, os Jovens Pesquisadores e Jovens Repórteres que foram catalisadores dessa participação juvenil.

\section{Participação juvenil nas políticas da SEMCTUR}

A institucionalização da Secretaria de Cultura e Turismo em Nova Iguaçu relatada rapidamente acima teve como principais atores a juventude da cidade. Foram gestadas no munícipio políticas específicas para este grupo. O principais projetos da secretaria que obtiveram impacto frente a juventude da cidade e que nos propomos a analisar, são o Jovem Repórter e o Jovem Pesquisador.

O Jovem Repórter consistia na seleção diária de jovens que ganhariam uma bolsa para custeio de sua participação nas reuniões semanais de pautas com locomoção na cidade para poste- 
rior produção textual, que constituiriam as matérias jornalísticas para um blog <culturani.blogspot.com>. Já o Jovem Pesquisador de Nova Iguaçu, consistia também na seleção diária de jovens para monitorar, através de técnicas de pesquisa, os projetos executados pela SEMCTUR, além de produzir dados estatísticos sobre a cidade.

Não é necessária a produção de um mapa para a demonstração que os jovens da periferia urbana são os mais afetados com as disparidades sociais brasileiras, principalmente, no que diz respeito ao acesso à educação e emprego. Com escasso acesso aos bens necessários à reprodução social, a juventude periférica brasileira, é alvo cada vez mais preferencial de programas elaborados pelo estado e projetos elaborados pelas ONGs e Terceiro Setor ${ }^{13}$.

Sendo assim, a partir dos projetos, ganha sentido o tema da mobilidade social, o aumento de possibilidades para estes jovens entra na pauta da discussão. O que antes estava restrito a juventude dos estratos médios da sociedade brasileira - a possibilidade de "usufruto" da juventude; a entrada tardia no mercado de trabalho (considerando a influência clara do desemprego) e a negociação com a família quando se adensam as mudanças e cortes geracionais - passam a fazer hoje parte da vida do jovem de periferia.

Tornam-se possíveis experimentações urbanas a partir da mobilidade e altera-se o quadro de possibilidades/planejamento, porque se alteram também o contato com suas redes, que, por sua vez contribuem para as possibilidades de trabalho/atuação. O poder de planejar, "ir e voltar" que antes estavam restritos aos jovens da classe média/alta, torna-se um dado a ser analisado, pois auxilia a descompressão do imaginário deste jovem.
Seguindo as orientações de Denise Cordeiro, no seu livro sobre a Juventude nas Sombras (2009), trata-se de perceber os indivíduos nos termos de Norbert Elias (1994), através de constelações de circunstâncias que podem alterar suas configurações sociais, a partir do debate que Elias trava sobre os conceitos de "individuo" e "sociedade" no cerne da Sociologia Relacional. As formulações de Elias - que fogem do estruturalismo bourdiano - nos permitem perceber que os indivíduos podem impactar redes de relacionamento anteriormente estabelecidas, o que modifica sua posição de classe, considerando seu território de partida.

Essa perspectiva nos ajuda a enxergar que houve modificações na vida desse grupo de jovens, algo foi modificado em suas subjetividades, quando inseridos nos diversos programas e ações governamentais. Deste modo, o trabalho com jovem e juventude de periferia, faz sentido à medida que emerge nesses últimos 8 anos uma "geração" que vive um momento político que impacta suas vidas em termos de construção de uma autonomia e de redes sociais próprias. Na fala dos próprios jovens:

Olha, eu vivia numa bolhazinha, sabe? Lá em Morro Agudo e estava em Nova Iguaçu e era isso, sabe? Para mim o que era importante... Não tinha nada. De importante não tinha nada. O mesmo discurso que ouço muito, sabe? "O que tem em Nova Iguaçu? Nada. Nova Iguaçu tem o Top Shopping, que tem aquele cinema horrível que só passa filme dublado, tem a RioSampa, tem uns barzinhos, o Silvio Monteiro que não faz guerra a muito tempo, embora exista lá. $E$ ai, eu percebi que não. Nova Iguaçu é muito grande. Nova Iguaçu vai muito além de certos eixos, quando você circula tanto. Então primeiramente eu estourei essa bolhazinha e circulei pela cidade, entende? Coisas que eu não fazia, poxa vida. 
Eu estudava de manhã, chegava em casa à tarde dormia e pronto, sabe? Era essa vidazinha de estudante, entende? Aí eu passei a circular, bem louca, porque eu ia para cada canto de Nova Iguaçu que a gente nunca tinha ouvido falar, entende? Comecei a ter contato com muita gente, (que dizia) que olha não é só isso, presta a atenção, que tinha um olhar... Eram donas de outros discursos, acabou me enchendo de muitas perspectivas. Eu acho que a partir desse momento, eu vi: peraí, não é só isso. O que passa sobre a minha cidade no jornal da Globo, no jornal do SBT, não é o único lado da moeda, não é a única coisa (...) Eu posso enxergar nas pessoas histórias, que talvez você não reconheça como importantes, uma pessoa produtora de cultura que talvez você mesmo não se reconheça, entende? Eu acho que me foi dado um novo olhar, uma nova maneira de enxergar as coisas, de pensar, de criticar e principalmente de ouvir bastante, sabe? Talvez deixe de criar uma própria opinião porque eu me misturo muito com a opinião dos outros, sabe? O importante as vezes não é nem falar, o importante as vezes é deixar os outros falarem. Acho que isso foi muito incitado em mim, estimulado, pessoalmente. (Jéssica Ramos, ex-Jovem Repórter, em entrevista concedida ao autor).

Todo dia eu conheço uma pessoa diferente, eu tenho um voo marcado hoje para as dez horas da noite, vou para São Paulo, dia 31 eu vou para a Bahia e dia sete eu vou para Recife, vou conhecer sete cidades em Recife. Então assim, toda hora buscando rede, entende? [...] (Yasmin Thayná, ex-Jovem Repórter, em entrevista concedida ao autor).

É óbvio que a juventude não é vivida da mesma maneira, especialmente a juventude das classes populares, em que não existe o tempo do planejamento pois são latentes as responsabilidades da vida adulta. No entanto, uma geração de jovens populares, mesmo que de forma incipiente e limitada, experimenta pela primeira vez a possibilidade de planejar, viver sua juventude não necessária e diretamente ligada ao mundo do trabalho.

A projeção do que será suas vidas não depende exclusivamente das condições materiais da existência. Estes jovens começam a ser apresentados a outros ritmos/aspirações. Apesar dos problemas do conceito de geração e de como a política a política se consolida numa perspectiva transescalar - já que existem poucos jovens nos projetos culturais - consideramos que diferentemente, por exemplo, de seus pais ou parentes próximos, de alguma maneira estes jovens "levantam suas cabeças" e começam a perceber possibilidades ao seu redor. Denominamos, de forma incipiente, essa geração como "Geração Ponto de Cultura”, que aos poucos se tornam sujeitos, nos termos de Touraine (1993), articulando um projeto de vida sem a necessidade de entrada imediata no mercado de trabalho.

É possível afirmar, a partir da experiência em Nova Iguaçu, que esse grupo especifico de jovens, adquiriram auto-respeito, favoreceram sua experiência social e tiveram respeitada sua condição de sujeito (RIBEIRO \& LOURENÇO, 2005). Sendo este um efeito imprevisto da política ministerial e das secretarias de cultura, já que seu objetivo inicial era apoiar projetos culturais consolidados. Não se esperava que os jovens aderissem de maneira tão intensa a essas políticas.

A grande questão talvez esteja colocada na percepção do que estes jovens estão fazendo e para onde estão indo. São jovens dentro de projetos de secretarias de governo em busca de oportuni- 
dades de expansão de seu conhecimento e com a esperança de inserção futura no mercado de trabalho. Tanto do lado dos gestores e formuladores da política como da juventude, existem contradições.

Primeiro, apesar dos efeitos benéficos da imprevisibilidade, não existe clareza com que o que se espera e se quer com os projetos culturais. Aliás, a própria ideia de projeto é problemática, foi comum nas entrevistas com os gestores a defesa do que estavam promovendo através da referencia aos princípios democráticos de participação. A democracia, neste contexto, é apresentada como produtora automática da igualdade.

No entanto, exagerando o exemplo, a democracia no caso apresentado é promotora de desigualdades, à medida que esses projetos aparecem, em grande parte, filiados a políticas compensatórias e a partidos políticos e suas gestões, sem que se pense, de fato, em desenvolvimento social. É preciso aproximar os projetos da esfera da ação social, repensar sua aura de atividade demarcada com um fim necessariamente marcado, coeso, efetivo e produtivo.

Especialmente hoje, quando vivemos como formulado por Ana Clara Torres Ribeiro (2006), uma crise societária - que fragiliza "os processos de socialização e orientações institucionais relacionadas à tessitura das interações sociais" - a conexão desses jovens com outras bases culturais e o possível "choque" produtor de uma luta identitária/autonomia fica menor quando o objetivo é falar somente sobre Nova Iguaçu e publicizar ações que ocorrem exclusivamente no município ${ }^{14}$.

Assumindo uma faceta esperançosa, reconhecemos uma juventude que não se deixa prender pelos cortes propostos nos projetos e está do outro lado das contradições. Em sua produção tex- tual e na sua fala, podemos identificar elementos e reflexões que estavam longe do que foi pedido/sugerido. Especialmente através do blog CulturaNI, os jovens foram além da divulgação dos projetos da SEMCTUR. Falaram das questões da cidade, do que os incomodava enquanto cidadãos metropolitanos; refletiram sobre arte e comunicação; e apesar de formados e formatados pelas aulas de produção textual não abandonaram e impuseram sua escrita:

Você já deve ter escutado muito blá, blá, blá dizendo que a leitura difunde informação, cultura, educação, valores democráticos e lazer, além de nos ajudar a desenvolver nossas capacidades criativas, de comunicação, de compreensão do mundo, melhora seu nível educativo e amplia nossos conhecimentos de forma agradável. Mas sei que, provavelmente, você deve achar isso um saco e prefere assistir um filme. Se esse for seu caso, isso provavelmente acorre porque você não teve incentivos para leitura. Talvez os seus pais não liam histórias pra você quando criança ou você era obrigado a ler os livros paradidáticos na escola. E tudo que é obrigatório, acaba se tornando chato. (Extrato de "O prazer em ler". Autoria de Raíze Souza).

Dobre a perna, se apoie nos joelhos, vá até o chão e se erga sem cair. Levante a camisa, mostre a barriga e a trema ou a mecha em ondas como uma dança do ventre. Gire, bata os pés e tenha ritmo. Se você conseguir todos esses movimentos você está apto a participar da disputa que vem fervendo as comunidades pacificadas do Rio de Janeiro. Moleques da periferia do Rio de Janeiro não precisam de preparo. Como algo genético, os meninos já nascem sendo experts em misturar frevo e funk em passos incrí- 
veis que caíram na rede e podem ser vistos no canal do Youtube. (Extrato de "A Cultura do Passinho". Autoria de Joyce Pessanha).

A esperança é o alimento que dá a energia suficiente para o homem cruzar novas fronteiras. É o caso das legiões de jovens que escrevem na proteção de seus quartos materializando ainda que amadoramente suas poesias, artigos ou letras de músicas. Protegidos pelo resignado e ao mesmo tempo incomodo anonimato. (Extrato de "Novos Tempos". Autoria de Leandro Oliveira).

É bem cedo. Há uma multidão se empurrando em busca de um valioso lugar sentado durante a sua viagem. Muitos se agridem de todas as formas possíveis, outros passam mal, choram e até desmaiam. O clima de revolta e descontentamento é geral. Sabe onde se passa esse filme? Isso mesmo, nos metrôs e trens espalhados por todo o Rio de Janeiro e parece que não sairá de cartaz nunca! Com uma rotina que começa dessa forma, não há tranquilidade e bom-humor garantido. E esse é apenas o começo de um difícil dia na saga de vários trabalhadores e estudantes. Literalmente, é começar com o pé esquerdo, que, geralmente, é pisoteado. (Extrato de "Pânico nos trilhos". Autoria de Joaquim Tavares).

Ao sair na rua você se liga que isso tudo é a América do Sul: os bares, a guerra civil e o calor. É aí que você entende que o sentimento é mais forte que qualquer barato. É complicado se encontrar como pensante nas questões sociais que envolvem viver no Rio. Vai além de sentir diariamente a miséria na pele - apesar de isso já ser mais que o bastante. É quase ter que escolher um lado: a polícia ou a guerrilha para militar, que já se tornou fatalmente ideológica. É um questionamento que envolve o jovem de uma maneira única. O funk, as drogas, a cultura marginal em suma... e aí?Em uma rápida troca de ideias com alguns jovens, percebe-se que as opiniões sobre a marginalia $X$ maquiagem social carioca revelam um fator em comum: a cultura da violência. (Extrato de "O jovem frente à cultura bipolar carioca”. Autoria de Vitória Tavares).

Devo ressaltar também a relevância da cultura alternativa ou underground na vida da juventude da Baixada Fluminense. Que muita das vezes é desvalorizada pelo poder público, assim a taxando como inferior e sem importância. Mas essa adesão dos jovens a esse tipo de manifestação cultural não é uma negligencia as "raízes brasileiras" e muito menos apenas um resultado de certa "soberania cultural" dos EUA. Mas uma necessidade de se encontrar como pessoa, individuo, único e singular. A música se torna um modo efetivo de expressar o que se sente. Tanto que a anos mobiliza paz, revoltas, risos e lágrimas. Por isso festivais de música, que sejam acessíveis, são totalmente necessários para a juventude da Baixada Fluminense. Que só consegue ter acesso a esse tipo de coisa saindo de sua cidade. (Extrato de "Funções do Rock". Autoria de Rodrigo Caetano).

A produção da juventude periférica longe dos estereótipos que foram legados ao espaço da periferia durante décadas, nos ajuda a enxergar que os jovens de classe popular não são tolos, mas fazem parte da produção contemporânea de cultura. Dentro dessa "Geração Pontos de Cultura", os jovens de Nova Iguaçu conseguiram desenvolver suas próprias táticas e práticas para li- 
dar com as oportunidades criadas a partir das políticas de cultura.

As oportunidades que aparecem hoje na periferia urbana, ainda descem como machados, cortando e definindo ações setorializadas. Nesse percurso, apesar da percepção do que se espera desse corte, percebemos também como nascem híbridos, como criam-se particularidades e singularidades. Nos textos expostos acima, há um hibrido muito claro entre a forma/estética em que se espera que o jovem se enquadre e escreva com a necessidade de falar sobre o que importa para eles enquanto jovens de periferia. Há uma mediação, exagerando a análise, entre dois mundos, um diálogo interclassista que produz esse hibrido. A principal diferença que agora o principal ator está na parte de baixo dessa escala.

O que identificamos, tomando a perspectiva da ação social, é que para análise dos processos de hibridização, sempre foi olhada a disputa identitária e seus resultados na cultura. Através da produção textual e cultural dos jovens, se faz necessário olhar para o sujeito, o agente da hibridização. Por isso, propomos a categoria político-filosófica do sujeito hibridador. Esta categoria, proposta para compreensão do papel dos jovens na conjuntura em tela, é filiada a duas outras categorias filosóficas criadas para entender a ação social em contextos populares: o "Homem Lento", de Milton Santos $^{15}$ e o "Sujeito Corporificado"16 de Ana Clara Torres Ribeiro.

O trabalho com os jovens, como eles leem e se apropriam das oportunidades foi construído através dessas figuras parecem retóricas, mas na verdade condensam potencialidades que se manifestam em parte e que permanecem também como potencialidades. Em outras palavras, existem forças de futuro que só po- dem ser referidas, a partir de categorias político-filosóficas.

Deste modo, o sujeito hibridador, pode ser uma figura para trabalhar com o jovem que não é repetitivamente isolado, não é carente necessariamente de informação. Na verdade, o jovem hoje, pode e tem mais formação prática do que o formulador da política cultura. Afinal de contas não se aprendem os meandros da área de cultura em bancos escolares. Isso significa que o jovem que pode ser uma potencia em grande parte desconhecida, principalmente na luta pelas oportunidades e aproveitamento do que já existe, mas já está em busca hoje pela realização do que deseja culturalmente.

\section{Conclusões}

Para além de todas as análises possíveis, talvez a que tenha maior importância seja demonstrar que a periferia sempre esteve viva. Tem sido historicamente "fácil" considerar os sujeitos da periferia urbana brasileira como dominados - tanto na sua face docilizada (das cadeiras no portão, do churrasco no fim de semana, da malandragem, do sujeito "de bem com a vida", entre tantos outros) quanto da face violenta que deve ser evitada e controlada (dos matadores, da vala, do "menor" delinquente) - que estão e estarão longe das disputas sobre este mesmo urbano.

Há uma atribuição de papéis ao Outro que é recorrente nas políticas socioculturais onde se define qual é a carência desse Outro, independentemente deste de maneira quase completa - determinado inclusive suas potencialidades. No entanto, este não é um processo construído sem resistências, como inicialmente pode-se supor.

Assim, jovens não necessariamente vinculados a regionalismos e localis- 
mos, podem desenvolver admiração pela cidade onde vivem e viver através dela, no mundo. E esta vivência, obtida através de mobilidades físicas e sociais, pode ser realizada através de um dos instrumentos mais antigos do mundo: a palavra.

A palavra, obviamente, sempre esteve presente nos espaços populares. Sempre esteve presente nas lutas e reivindicações urbanas por emprego, moradia, saúde, educação e saneamento que sempre estiveram na pauta da Baixada Fluminense. A diferença talvez esteja no uso da palavra como estratégia ou pelo menos potencialmente portadora de uma estratégia que se relaciona com as oportunidades que aparecem nesses espaços durante os anos 2000.

Chega de relacionar à periferia e as classes populares à negação de sensos de realidade, existentes em toda relação social: não há inocência nessa relação, a dominação sempre foi percebida e estratégias de rompimento sempre tentadas.

As relações sociais colocadas em tela, entre os portadores/gestores de recursos culturais e os jovens da cidade não são simples. Acreditamos que nem todos jovens são hibridadores e que muitos aceitam a política cultural como ela é e chegou, sem a necessidade de rupturas. No entanto, não cabe ao pesquisador propor interpretações dentro da ótica das classes dominantes. Não interessa considerar esse jovem como um ser "parado", "improdutivo" e/ou "sem perspectivas".

Interessa-nos a identificação de hibridadores, principalmente e sobretudo, para a identificação de resistências sociais que não são abstratas, pela percepção e interpretação de gestos do Outro. A resistência e a denuncia da situação juvenil, sempre esteve nas ruas - está na luta pelo passe livre, pela luta de liberdade de expressão nas favelas cariocas, no "passinho do menor", está nos arrastões de Londres, nos carros queimados em Paris - esse é o seu lugar mas óbvio, mas também pode estar (porque não?) em um texto.

Em Nova Iguaçu, o texto ajudou a juntar o tradicional e a hipermodernidade, conseguiu concretizar a resistência num espaço-tempo real. Esse híbrido está sendo feito hoje por uma juventude que ainda está nas sombras (CORDEIRO, 2009) e dentro de projetos específicos de governo, mas pode formar atores que qualificam ações tradicionais de reivindicação e protesto.

Talvez esse momento seja único no sentido que os jovens de origem popular, apesar das condições materiais nos quais estão postos, experimentaram processos de singularização que os movimentaram intelectualmente de várias maneiras: a partir do questionamento do que é sua cidade, as diferenças entre os espaços em que estão inseridos, a possibilidade de seguir estudando, entre outras. Como bem ressalta Denise Cordeiro (2009): "Do mesmo modo que se rendem as glórias do consumo, tentam escapar produzindo ações microscópicas de resistência, criando lugares de vida potentes".

Deste modo, nossa tarefa é tentar olhar para essas "ações microscópicas" e fomentar maneiras inovadoras de participação e atuação em busca de um projeto político que seja elaborado e idealizado por estes jovens a partir de suas experiências de vida concreta. Trata-se de romper com homogeneizações e considerar a juventude como diversa nas proposições de ações que possam colocá-la como sujeitos que assumirão a história de suas cidades.

O envolvimento com as ações/políticas culturais podem ser o início da construção desse projeto. Isso, no entanto, só o tempo nos dirá. 


\section{Bibliografia}

BARRETO, Alessandra Siqueira; Cartografia política: as faces e fases da política na Baixada. Fluminense, Rio de Janeiro: UFRJ/ MN, 2006.

BOURDIEU, Pierre. O Poder Simbólico. Rio de Janeiro. Bertrand Brasil, 1999.

CALDEIRA, Teresa Pires do Rio. A política dos outros: o cotidiano dos moradores da periferia e o que pensam do poder e dos poderosos. São Paulo, Brasiliense, 1984.

CALDEIRA, Teresa Pires do Rio. Cidade de muros: crime, segregação e cidadania em São Paulo. São Paulo: Edusp, 2000.

CASTELLS, Manuel. A questão urbana. São Paulo, Paz e Terra, 1983.

CORDEIRO, Denise Maria Antunes. Juventude nas sombras: escola, trabalho e moradia em territórios de precariedades. Rio de Janeiro, Lamparina. 2009.

DURHAM, E. A sociedade vista da periferia. In: A dinâmica da cultura: ensaios de antropologia. São Paulo, Cosac Naify, 2004.

ELIAS, Norbert. A sociedade dos indivíduos. Rio de Janeiro: Jorge Zahar Editor, 1994.

FRÚGOLI JUNIOR, Heitor. O urbano em questão na antropologia: interfaces com a sociologia. Revista de Antropologia, São Paulo, v. 48, n. 1, 2005.

GOTTDIENER, Mark. A produção social do espaço urbano. São Paulo, EDỦSP, 1997.

LAGO, Luciana Correa do. A periferia metropolitana como lugar do trabalho: da cidade-dormitório à cidade plena. Cadernos IPPUR/ UFRJ, Rio de Janeiro, v. 22, 2007.

LEFEBVRE, Henri. A Reprodução das relações de produção. Porto: Publicações Escorpião, 1973.

LIMA, Vinícius Carvalho. Juventude e Política Culturas nas Periferias do Presente: o caso de Nova Iguaçu. 2012. Dissertação (Mestrado em Planejamento Urbano e Regional) - Instituto de Pesquisa e Planejamento Urbano e Regional, Universidade Federal do Rio de Janeiro, Rio de Janeiro, 2012
MAGNANI, José Guilherme Cantor. Trajetos e trajetórias: uma perspectiva da antropologia urbana. Sexta-feira, n 8, São Paulo, 2006.

MARTINS, José de Souza. A sociabilidade do homem simples. São Paulo: Hucitec, 2000.

NASCIMENTO, Érica Peçanha do. A periferia de São Paulo: revendo discursos, atualizando o debate. Revista RUA [online], no. 16, 2010.

PAVIANI, Aldo. A lógica da periferização em áreas metropolitanas. In: SANTOS, Milton; SOUZA, Maria Adélia A. (Org.). Território, globalização e fragmentação. São Paulo: Hucitec, 1994.

POLLI, Simone A. Curitiba, metrópole corporativa: fronteiras da desigualdade. 2006. Dissertação (Mestrado em planejamento Urbano e Regional)-Instituto de Pesquisa e Planejamento Urbano e Regional, Universidade Federal do Rio de Janeiro, Rio de Janeiro, 2006.

RIBEIRO, Ana Clara Torres. A cidade neoliberal: crise societária e caminhos da ação. Observatório Social de América Latina, v. 21, 2006.

RIBEIRO, Ana Clara Torres. Dança de sentidos: na busca de alguns gestos. In: Corpocidade: debates, ações e articulações. Organização: Paola Berenstein Jacques, Fabiana Dultra Britto. - Salvador: EDUFBA, 2010.

RIBEIRO, Ana Clara Torres. Território Usado e Humanismo Concreto: O Mercado Socialmente Necessário. X Encontro de Geógrafos da América Latina, 2005.

RIBEIRO, Ana Clara Torres; LOURENÇO, A. Marcas do tempo: violência e objetivação da juventude. Jovens em Tempo Real, Rio de Janeiro, Lamparina.

SANTOS, Carlos Nelson Ferreira (Org.). Quando a rua vira casa. São Paulo: Projeto, 1985.

SANTOS, Milton. A cidade nos países subdesenvolvidos. Ed. Civilização Brasileira, Rio de Janeiro, 1965.

SANTOS, Milton. Técnica, espaço, tempo: globalização e meio técnico-científico informacional. São Paulo, Hucitec, 1994. 
SARAIVA, Camila Pereira. A periferia consolidada em São Paulo: categoria e realidade em construção. 2008. Dissertação (Mestrado em planejamento Urbano e Regional)Instituto de Pesquisa e Planejamento Urbano e Regional, Universidade Federal do Rio de Janeiro, Rio de Janeiro, 2008.

SIMÕES, Manoel Ricardo. A cidade estilhaçada: reestruturação econômica e emancipações municipais na Baixada Fluminense. Mesquita: Entorno, 2007.

TOURAINE, A. Juventud y Sociedad en Chile. RICS. 137, set. 1993.

VIANNA, Hermano. O Mundo do Funk Carioca. Rio de Janeiro, Jorge Zahar Editor. 1997.

1 Vinícius Carvalho Lima é graduado e licenciado em Ciências Sociais pelo Instituto de Filosofia e Ciências Sociais da Universidade Federal do Rio de Janeiro (IFCS/UFRJ) e Mestre em Planejamento Urbano e Regional (IPPUR/UFRJ). Foi integrante do Laboratório da Conjuntura Social Tecnologia e Território (LASTRO/IPPUR/UFRJ) coordenado pela Profa. Dra. Ana Clara Torres Ribeiro. Tem experiência em Sociologia Urbana, atuando nas seguintes temáticas: ação social coletiva, política cultural, juventude, periferia urbana, reivindicação e protestos urbanos. Hoje integra o Núcleo de Estudos de Teoria Social e América Latina (NETSAL/IESP/UERJ)

2 O Laboratório da Conjuntura Social: tecnologia e território, criado em julho de 1996, no Instituto de Pesquisa e Planejamento Urbano e Regional (IPPUR) da Universidade Federal do Rio de Janeiro, tem, por principal finalidade, a valorização da ação social e dos estudos de conjuntura na pesquisa urbana, no momento em que a reestruturação econômica, apoiada nos fluxos informacionais e em novas orientações administrativas, altera oportunidades sociais, funções metropolitanas e o teor sociocultural da vida coletiva. O LASTRO encontra-se organizado em torno de uma proposta de trabalho eminentemente metodológica e transdisciplinar, que inclui o alcance de passagens analíticas, de difícil execução, entre esferas, níveis e escalas da experiência urbana brasileira. No desvendamento de uma metodologia adequada à análise de conjuntura comprometida com a dinâmica urbana, valoriza-se o ângulo da ação, onde outras opções analíticas privilegiam mudanças técnicas e tendências exclusivamente econômicas - <lastroufrj.com.br>.

3 Entre estudos destaca-se a primeira incursão de Milton Santos na temática do subdesenvolvimento, intitulado: "A cidade nos países subdesenvolvidos", de 1965.
4 Importante ressaltar que as teorias marxistas urbanas surgiram como uma tentativa de responder e reorientar os estudos da Escola de Chicago e teve ampla aceitação na produção teórica brasileira. Incorporou orientações teóricas da Economia Política aos estudos urbanos. Passou-se a considerar, então, os mecanismos de exploração e opressão gerados pelo modo de produção capitalista, que não aparecem na reprodução quase "natural" das cidades na análise da Escola de Chicago.

5 José de Souza Martins, por exemplo, utilizando a matriz lefebvriana, reflete acerca das classes populares e das situações de risco que podem estimular a formulação de uma visão crítica que auxilie a integração social de uma população constantemente ameaçada pela corrosão de suas condições de vida. Considerando que os indivíduos são capazes de perceber os processos de mudança em que estão inseridos, é possível também considerar a possibilidade de que se tornem sujeitos ativos em lutas que vierem impedir que as mudanças, inevitáveis, reproduzam a injustiça social: "É no fragmento de tempo do processo repetitivo produzido pelo desenvolvimento capitalista, o tempo da rotina, da repetição e do cotidiano, que essas contradições fazem saltar fora o momento da criação e de anúncio da História - o tempo do possível. E, que, justamente por se manifestar na própria vida cotidiana, parece impossível. Esse anúncio revela ao homem comum, na vida cotidiana, que é na prática que se instalam as condições de transformação do impossível em possível (MARTINS, 2000, p. 15).

6 Destacamos a Antropologia da Universidade de São Paulo e autores como Durham (1986), Teresa Pires do Rio Caldeira (1984), Frugóli (2005) e Magnani (2006). Destacamos, ainda, um trabalho seminal nesse tipo de abordagem eminentemente etnográfica e microssociológica, o livro "Quando a rua vira casa" (MELLO, VOGEL; FERREIRA DOS SANTOS, 1981). Ainda é necessário destacar, Gilberto Velho por sua obra e pioneirismo e Hermano Vianna pelo seu trabalho com juventude e manifestações culturais cariocas nas décadas de 1990 e 2000.

7 Para melhor contextualização dessa centralidade das políticas culturais no mundo e Brasil, recomendamos a leitura da dissertação de mestrado que deu origem ao artigo: "Juventude e Políticas Culturais nas Periferias do Presente: o caso de Nova Iguaçu".

8 A intenção com a assimilação desse conceito/noção foi dar visibilidade e/ou a compreensão de outras modalidades de cultura - populares, afrodescendentes e indígenas - frente à já consolidada cultura erudita. Gil falava muito à época do que batizou "do-in antropológico" que consistia na ideia de universalizar os serviços culturais, com a presença de centros culturais, bibliotecas e telecentros em todo o país, a começar pelas regiões mais pobres e distantes; valorizar e dar autonomia para as diversas formas de manifestação cultural 
existentes no país, não somente as institucionalizadas e consagradas pela elite e a indústria cultural; buscar novas possibilidades de interlocução e diálogo com outras instâncias da sociedade, por meio de inserção econômica e desenvolvimento local.

9 A execução das políticas ficou a cargo de estados e municípios

10 Foram marcantes os casos da Educação e Cultura onde assumiram Jailson de Souza e Marcus Vinícius Faustini especialistas e militantes atuantes nas respectivas áreas.

11 Como, por exemplo, o Banco Interamericano de Desenvolvimento (BID) de onde recebeu US\$ $69 \mathrm{mi}-$ Ihões para o Programa de Saneamento Ambiental (Prosani).

12 O Movimento Enraizados foi criado com o intuito de colocar em contato pessoas de todo o Brasil que praticassem as artes integradas do hip hop (rap, break, dj e graffiti), divulgando cada artista e promovendo a cultura e a inclusão social através da militância nas periferias das grandes cidades. Pensando nessa nova forma de interatividade, diversas ferramentas foram criadas para a comunicação "com" e "entre" os integrantes do hip hop, comunicação esta que cresceu ainda mais a partir da criação do Portal Enraizados na Internet < www. enraizados.com.br >, no ano 2000 , colocando a organização como referência juvenil na comunicação alternativa. Fonte: Site do Movimento Enraizados. Acessado em 15/12/2011.

13 Defendemos que as políticas para juventude foram pensadas através de adjetivos que serviram muito bem à definição de políticas públicas, na medida em que "definiram" e "qualificavam" os jovens. No entanto, contribuíram muito pouco para a consideração da diversidade de relações e interesses em que estão inseridos os jovens. Todo comportamento que se afasta do público alvo, do padrão, deve ser desconsiderado em nome da eficiência da política pública. Felizmente as relações sociais não permitem tais simplificações, a juventude/ jovem não terão características definidas a priori.

14 Não culpabilizamos os gestores dos projetos de Nova Iguaçu, até porque estes tentaram implementar um novo modo de enxergar e compreender a própria cidade. O problema está no fato de que as ambiguidades e contradições que estão no cerne dessas políticas, cada vez mais pendem a uma certa "eficiência capitalista", que liga identidades à negócios. No entanto, a questão torna-se dramática, a medida que a possibilidade de surgimento de sujeitos propositivos, capazes de ação política é eclipsada. Existe um olhar, que de um lado valoriza a juventude e pelo outro a lê como sendo foco de problemas que devem ser tratados. Existem momentos de estimulação honesta da imaginação do Outro, que logo é convertida em tentativas de enquadrá-lo e normatizá-lo.
15 O Homem Lento foi elaborado pelo geógrafo Milton Santos (1994) em sua discussão sobre técnica, espaço e tempo. A categoria busca personificar o homem comum, pobre, do lugar, que, no ambiente das metrópoles dependentes, resiste às forças globalizantes, externas e verticais. O homem lento, que não domina o saber moderno, pode inventar outro território e também levar à mudanças. O autor diz que "O tempo concreto dos homens é a temporalização prática, movimento do mundo dentro de cada qual e, por isso, interpretação particular do tempo por cada classe social, cada indivíduo" (SANTOS, 1994, p. 83). O homem lento que conhece os lugares, que necessita deste conhecimento para a sobrevivência e que, portanto, constrói, em meio a todos os desafios, o período histórico que sucederá o que vivemos - o período popular da história.

16 O sujeito corporificado aparece nas análises da socióloga Ana Clara Torres Ribeiro desenvolvidas no campo da saúde e se consolida a partir do contato com o urbanismo de face insurgente. O sujeito corporificado, portanto, aparece como o sujeito de direitos - figura clássica da sociologia marxista - materializado "em sangue, carne e cultura, permitindo a radical superação do idealismo e do materialismo objetivante" (RIBEIRO, 2000). Para Ana Clara, a apresentação na cena política mundial do drama humano exigirá a formulação de estratégias efetivas para a realização de um movimento de superação, ou seja, "o encontro de uma nova síntese que reúna corpo e espírito (valores e orientação ética) na construção da democracia" (RIBEIRO, 2000). A partir da interface com a temática cultural e o urbanismo, a definição do sujeito corporificado, passa a estar vinculado ao aparecimento propositivo na cidade, através da superação da individualidade, do silêncio e em ações possíveis: "O sujeito corporificado, ao desafiar controles da experiência urbana e a burocratização da existência, alcança o direito à definição de sua forma de aparecer e acontecer. Nas palavras de Alain Badiou: "Um sujeito é primeiramente aquilo que fixa um evento indecidível, porque assume o risco de decidí-lo" (1994:45). Esse sujeito transforma-se em acontecimento, onde e quando são esperados o seu silêncio e o apagamento da sua individualidade. O sujeito corporificado tomaria, portanto, o teatro da vida nas suas mãos, opondo-se à sua desmaterialização em papéis repetitivos, em imagens reiterativas e em modelos de cidade (e de urbanidade) que o excluem. Esse sujeito - que emerge, de forma incidental, na cidade comandada pela espetacularização da vida coletiva - ensina que a procura da transcendência permanece latente nos encadeamentos do cotidiano". (RIBEIRO, 2006, p. 32). 